\title{
Epigenetic modifications in human thyroid cancer (Review)
}

\author{
BITA FAAM $^{1}$, MOHAMMAD ALI GHAFFARI ${ }^{2}$, ATA GHADIRI $^{1,3}$ and FEREIDOUN AZIZI ${ }^{4}$ \\ ${ }^{1}$ Cellular and Molecular Research Center, Jundishapur University of Medical Sciences, Ahvaz; \\ ${ }^{2}$ Cellular and Molecular Research Center, Department of Biochemistry, School of Medicine; \\ ${ }^{3}$ Department of Immunology, Faculty of Medicine, Jundishapur University of Medical Sciences, Ahvaz; \\ ${ }^{4}$ Endocrine Research Center, Research Institute for Endocrine Science, \\ Shahid Beheshti University of Medical Sciences, Tehran, Iran
}

Received August 27, 2014; Accepted September 9, 2014

DOI: $10.3892 /$ br.2014.375

\begin{abstract}
Thyroid carcinoma is the most common endocrine malignancy of the endocrine organs, and its incidence rate has steadily increased over the last decade. Over $95 \%$ of thyroid carcinoma is derived from follicular cells that have a spectrum of differentiation to the most invasive malignancy. The molecular pathogenesis of thyroid cancer remains to be clarified, although activating the RET, RAS and BRAF oncogenes have been well characterized. Increasing evidence from previous studies demonstrates that acquired epigenetic abnormalities participating with genetic alteration results in altered patterns of gene expression/function. Aberrant DNA methylation has been established in the $\mathrm{CpG}$ regions and microRNAs (miRNAs) expression profile recognized in cancer development. In the present review, a literature review was performed using MEDLINE and PubMed with the terms 'epigenetic patterns in thyroid cancer [or papillary thyroid carcinoma (PTC), follicular thyroid carcinoma (FTC), medullary thyroid cancer (MTC), anaplastic thyroid cancer (ATC)]', 'DNA methylation in thyroid cancer (or PTC, FTC, MTC, ATC)', 'miRNA expression in thyroid cancer (or PTC, FTC, MTC, ATC)', 'epigenetic patterns in cancer' and the current understanding of epigenetic patterns in thyroid cancer was discussed.
\end{abstract}

\section{Contents}

1. Introduction

2. Epigenetic patterns in cancer

3. Epigenetic modification in thyroid cancers

4. Conclusion

Correspondence to: Dr Mohammad Ali Ghaffari, Cellular and Molecular Research Center, Department of Biochemistry, School of Medicine, Jundishapur University of Medical Sciences, Golestan Street, Ahvaz, Iran

E-mail: ghaffarima@yahoo.com

Key words: epigenetic, DNA methylation, microRNA, thyroid cancer

\section{Introduction}

Thyroid carcinoma is the most common endocrine malignancy and accounts for $\sim 1 \%$ of all types of human cancer, with a rapid incidence rate reported worldwide (1). Over $95 \%$ of thyroid carcinomas are derived from follicular epithelial cells (2). They have been traditionally classified as well-differentiated thyroid carcinoma, including papillary (80\%) and follicular thyroid carcinoma (PTC and FTC, respectively) $(10-15 \%)(3)$. By contrast, poorly differentiated $(2,4)$ and anaplastic thyroid carcinoma account for $1-2 \%$ of thyroid malignancies. Medullary thyroid carcinoma (3\%; MTC) is a malignancy of parafullicular $\mathrm{C}$ cells that are derived from neural crest and occurs in sporadic (75\%) and hereditary (25\%) types (5). This wide spectrum of progression has been closely linked with the pattern of cumulative genetic and epigenetic alterations, which are correlated with tumor differentiation, metastasis and invasion (6). In thyroid carcinoma, the majority of genetic alterations initiate their functions through activating metabolic pathways. Constitutive activation of the mitogen-associated protein kinase (MAPK)/extracellular signal-regulated kinase (ERK) pathway leads to tumorigenesis and promotes cell division (7). Activation of this pathway is a common and important mechanism in the initiation and progression of human cancers. Genetic defects in the $R E T / P T C, B R A F$ and $R A S$ genes are associated with thyroid tumorigenesis. The prevalence of activating mutations in the $R A S$ gene are dependent on the tumor histology. For instance, certain studies showed that $R A S$ mutations are more frequent in FTC than PTC (8). RET proto-oncogene is responsible for encoding a cell membrane receptor tyrosine kinase (9). Ligands of this kinase have been reported as belonging to the glial-cell-line derived neurotropic factor family that causes receptor dimerization upon binding, leading to autophosphorylation of tyrosine residues and initiation of the MAPK/ERK pathway signaling cascade (10). RET functional deficiency results in Hirschsprung's disease; however, an increase in its activities is associated with numerous types of human cancer, including MTC $(11,12)$. Concurrent RET/PTC and $B R A F$ mutations have been reported in PTC $(7,13)$. The $B R A F$ V600E mutation, which is the sporadic form of these mutations, is restricted to papillary, anaplastic and poorly differentiated thyroid carcinoma $(14,15)$. The objective of 
the present study was to review the current understanding of epigenetic patterns in thyroid cancer.

Study criteria. The terms 'epigenetic patterns in thyroid cancer [or PTC, FTC, MTC, anaplastic thyroid cancer (ATC)]', 'DNA methylation in thyroid cancer (or PTC, FTC, MTC, ATC)', 'microRNA (miRNA) expression in thyroid cancer (or PTC, FTC, MTC, ATC)', and 'epigenetic patterns in cancer' were used in the MEDLINE and PubMed search for studies published between 1970-2014. All the abstracts were reviewed. The studies published in English were included if appropriately designed. The studies of abstracts meeting the criteria were subsequently reviewed to identify the details of the materials associated with the epigenetic patterns of cancer, in particular DNA methylation and miRNAs expression in thyroid cancer. The strategy used to search for studies was developed with the assistance of a research librarian at the Jundishapour University of Medical Science (Ahvaz, Iran).

Study selection. The following criteria were considered as essential for a study to qualify for inclusion in the present review: i) Correct cross-sectional study design involving case-control; and ii) review studies by a permanent scholar. All the studies were initially potential candidates for inclusion; however, they were excluded if they lacked appropriate study design.

\section{Epigenetic pattern in cancers}

Epigenetic mechanisms are essential for normal cell development and the maintenance of tissue-specific gene expression patterns in mammals (16). However, epigenetic modifications can result in inappropriate activity or inhibition of various signaling pathways, leading to cancer. According to previous studies, epigenetic modification is reported in numerous types of cancers, in addition to a number of genetic variations (17-20). Epigenetic patterns include the covalent modification of chromatin, DNA cytosine methylation, non-coding RNAs expression and nucleosome remodeling (21). Aberrant DNA methylation is associated with gene expression and plays an important role in tumorigenesis (22). Hypomethylation leads to genomic instability and activation of proto-oncogenes through a variety of mechanisms, which contribute to cancer development and progression. However, hypermethylation is associated with gene silencing, particularly tumor suppressor genes, and it is considered to be the hallmark of cancers (23). The ability of hypermethylation is well recognized; however, the mechanism through which genes are targeted for hypermethylation is unclear. Further understanding of how specific genomic regions are targeted for hypermethylation will potentially result in the design of additional therapeutic regions.

Another epigenetic modification is the miRNA expression profile. In a previous study the expression profile of miRNAs in tumors was compared to the associated normal tissues, indicating wide-spread changes in the expression level (24). Since miRNAs regulate the expression of numerous genes that are involved in the transcriptional regulation, cell proliferation and apoptosis, alteration in their expression can promote tumorigenesis. miRNAs may function as either tumor suppressors or oncogenes, depending on their effect on the target genes.
Various mechanisms, including chromosomal abnormalities, transcription factor binding and epigenetic alteration, are important in miRNA expression.

\section{Epigenetic modification in thyroid cancers}

DNA methylation. Aberrant DNA methylation of tumor suppressor genes and proto-oncogenes are common in thyroid tumors, and it occurs in a number of other human tumors. Certain specific tumor suppressor genes in the thyroid are PTEN, RASSF1A, TIMP3, SLC5A8, DAPK, RAP 32 and RAPIGAP (Table I).

$P T E N$ was identified as a tumor suppressor gene, which is mutated in a large number of cancers. This gene encodes the phosphatidylinositol-3, 4, 5-triphosphate 3-phosphatase protein. PTEN negatively regulates the AKT/PKB signaling pathway and is involved in the regulation of cell cycle, opposing cell growth and rapid division $(25,26)$. Aberrant DNA methylation in this gene is mostly reported in PTC and FTC (27).

The RASSF1A gene encodes a protein that is similar to the RAS effector protein (28). The altered expression of this gene is associated with cancer, and aberrant DNA methylation has been identified as an important mechanism in the inactivation of this gene $(29,30)$. In contrast to FTC, only a small proportion of PTC harbored the aberrant methylation of RASSF1A, which may have a critical role in thyroid tumorigenesis, independent of the BRAF/MAPK kinase (MEK) MAPK pathway (30).

TIMP3 is a tissue inhibitor of metalloproteinase, which inhibits the growth, angiogenesis, invasion and metastasis of several tumors (31). This gene has been reported to be hypermethylated in thyroid cancer $(32,33)$ and is associated with extra thyroidal invasion and lymph node metastasis (33). The RAPIGAP gene encodes a type of GTPase-activating protein that downregulates the activity of the RAS-related protein. $R A P I G A P$ is implicated in the regulation of mitogenic and oncogenic pathways in thyroid cells $(34,35)$.

RAP1 has an important role in the regulation of the ERK-dependent pathway and activation of the BRAF-MEK-ERK pathway (36-38). The immunohistochemistry assay data showed the decreased expression of RAPIGAP gene in PTC (39), which was associated with its proliferation and invasion in thyroid cancer cell lines (40). Additionally, DNA hypomethylation has an important role in tumorigenesis; however, its role is not well understood. In this regard, Rodríguez-Rodero et al (41) aimed to determine the global patterns of aberrant DNA methylation in thyroid cancer using DNA methylation arrays. The study identified 262 and 352 hypermethylated and 13 and 21 hypomethylated genes in PTC and FTC, respectively. In addition, 280 and 393 hypomethylated genes and 86 and 131 hypermethylated genes were identified, which were determined in anaplastic and MTC, respectively. Among these genes, four oncogenes (INSL4, DPPA2, TCL1B and NOTCH4) were frequently regulated by hypomethylation.

Furthermore, a member of the serine protease inhibitor superfamily, mammary serine protease inhibitor (Maspin), which is encoded by the SERPINB5 gene, is a unique tumor suppressor gene, as it has a variety of biological behavior and function. The expression of this gene is regulated by epigenetic 
Table I. DNA methylation prevalence of thyroid-related genes in thyroid cancers.

\begin{tabular}{|c|c|c|c|c|}
\hline Genes & Function & $\begin{array}{l}\text { DNA methylation } \\
\text { prevalence }\end{array}$ & Author (year) & (Refs.) \\
\hline \multicolumn{5}{|c|}{ Tumor suppressor } \\
\hline PTEN & $\begin{array}{l}\text { PTEN is involved in the regulation of } \\
\text { cell cycle and preventing cells } \\
\text { from growing and dividing rapidly }\end{array}$ & $\begin{array}{l}50 \% \text { of PTC, } \\
100 \% \text { of FTC }\end{array}$ & Alvarez-Nuñez et al (2006) & $(27)$ \\
\hline RASSF $1 A$ & $\begin{array}{l}\text { RASSF } 1 A \text { localizes to microtubules } \\
\text { and promotes their stabilization }\end{array}$ & $\begin{array}{l}30 \% \text { of thyroid } \\
\text { cancers }\end{array}$ & Xing et al (2004) & $(30)$ \\
\hline TIMP3 & Tissue inhibitor of metalloproteinase & $53 \%$ of PTC & Hu et al (2006) & $(33)$ \\
\hline SLC5A8 & Sodium solute symporter family & $33 \%$ of PTC & Hu et al (2006) & $(33)$ \\
\hline$D A P K$ & $\begin{array}{l}\mathrm{Ca} / \text { calmodulin-dependent } \\
\text { ser/thr kinase protein }\end{array}$ & $34 \%$ of PTC & Hu et al (2006) & $(33)$ \\
\hline$R A P \beta 2$ & Negative regulator of cell growth & $22 \%$ of PTC & Hu et al (2006) & $(33)$ \\
\hline$R A P 1 G A P$ & RAP1GTPase-activating protein & $\begin{array}{l}72 \% \text { of PTC, } \\
38 \% \text { of FTC }\end{array}$ & Zuo et al (2010) & $(56)$ \\
\hline \multicolumn{5}{|l|}{ Oncogenes } \\
\hline INSLA & Belongs to the insulin and IGF family & $60 \%$ of MTC & Rodríguez-Rodero et al (2013) & $(41)$ \\
\hline$D P P A 2$ & Developmental pluripotency-associated 2 & $30 \%$ of MTC & Rodríguez-Rodero et al (2013) & $(41)$ \\
\hline$T C L 1 B$ & $\begin{array}{l}\text { An oncogene frequently activated by } \\
\text { reciprocal translocations }\end{array}$ & $64 \%$ of ATC & Rodríguez-Rodero et al (2013) & $(41)$ \\
\hline $\mathrm{NOTCH} 4$ & $\begin{array}{l}\text { A member of notch family, which plays a } \\
\text { role in a variety of developmental processes }\end{array}$ & $45 \%$ of ATC & Rodríguez-Rodero et al (2013) & $(41)$ \\
\hline Maspin & $\begin{array}{l}\text { A member of serine protease } \\
\text { inhibitor superfamily }\end{array}$ & $\begin{array}{l}100 \% \text { of WDTC, } \\
38 \% \text { of UDTC }\end{array}$ & Ogasawara et al (2004) & $(42)$ \\
\hline \multicolumn{5}{|c|}{ Thyroid specific } \\
\hline NIS & Sodium/iodide symporter & $\begin{array}{l}53.8 \% \text { of thyroid } \\
\text { cancers }\end{array}$ & Stephen et al (2011) & $(57)$ \\
\hline $\operatorname{Tg}$ & Thyroglobulin molecule & NA & NA & \\
\hline$T P O$ & Thyroid peroxidase & NA & NA & \\
\hline TSHR & Thyroid stimulating receptor & $\begin{array}{l}59 \% \text { of PTC } \\
47 \% \text { of FTC }\end{array}$ & $\begin{array}{l}\text { Xing et al (2003), } \\
\text { Eze et al (2011) }\end{array}$ & $\begin{array}{l}(43) \\
(45)\end{array}$ \\
\hline
\end{tabular}

PTC, papillary thyroid cancer; FTC, follicular thyroid cancer; MTC, medullary thyroid cancer; ATC, anaplastic thyroid cancer; WDTC, well-differentiated thyroid carcinoma; UDTC, undifferentiated thyroid carcinoma; NA, not available.

modification in a cell-type-specific manner. For the first time, Ogasawara et al (42) examined the DNA methylation status in the promoter region of Maspin, indicating that the overexpression of this gene, as a result of DNA hypomethylation, is closely associated with morphological dedifferentiation in thyroid cancers.

In addition to tumor suppressor genes and oncogenes, the expression of thyroid specific genes is frequently absent in thyroid cancer. Although the molecular mechanisms underlying the silencing of these genes are not well understood, aberrant DNA methylation could be considered as an important mechanism. For instance, hypermethylation, which leads to the silencing of NIS and TSHR gene, is frequently reported (43). Loss or altered expression of thyroid-specific genes is associated with the progression and dedifferentiation of thyroid cells, resulting in various thyroid diseases $(44,45)$. Therefore, aberrant methylation of these genes may be a pathogenesis or progression factor for thyroid cancers. Of note, this biological mechanism is associated with thyroid tumorigenesis, and the methylation pattern of these genes is also relevant to unsuccessful radioiodine therapy as the main medical treatment for this cancer (46).

miRNA expression profile. In normal or tumor cells with distinct biological properties, miRNAs identify the cell origin of different tumors; however, it remains unknown whether various tumors, which originate from the same cells, have different miRNA expression profiles. Consequently, thyroid tumors represent a suitable model for this study, as thyroid cancers encompass several tumors with different histology and degree of differentiation. Therefore, comparing the expression profile of miRNAs in normal and tumor thyroid cells may be a useful factor for diagnosis of thyroid malignancy (Table II).

miRNA expression in PTC. Previous studies that assessed the expression profile of miRNAs in PTC reported that the expression of $m i R-146, m i R-221, m i R-222, m i R-21$ and miR-181a increased in PTC compared to normal thyroid cells. Particularly, miR-146, miR-221 and miR-222 showed a 9-11-fold 
Table II. A summary of microRNAs (miRNAs or miRs) expression and their target gene in thyroid cancers.

\begin{tabular}{|c|c|c|c|c|c|}
\hline miRNA & Location & Description & $\begin{array}{l}\text { Notable target } \\
\text { genes in } \\
\text { thyroid cells }\end{array}$ & Author (year) & (Refs.) \\
\hline$m i R-146 a$ & $5 q 34$ & $\begin{array}{l}m i R-146 a \text { is involved in the feedback system } \\
\text { of the classical NF- } \mathrm{B} \text { signal pathway in PTC }\end{array}$ & PRKCE & Zhang et al (2014) & $(58)$ \\
\hline miR-221 & Xp11.3 & Oncogenic microRNA & $P 27$ & Visone et al (2007) & $(59)$ \\
\hline $\operatorname{miR}-222$ & Xp11.3 & Regulates p27 expression and thereby cell cycle & $P 27$ & Visone et al (2007) & $(59)$ \\
\hline$m i R-21$ & $17 q 23.2(54)$ & $\begin{array}{l}m i R-21 \text { has an important role in oncogenic } \\
\text { Ras-induced cell proliferation }(55)\end{array}$ & $\begin{array}{l}\text { PTEN, } \\
\text { PDCD4, } \\
\text { RhoB }\end{array}$ & $\begin{array}{l}\text { Meng et al (2007), } \\
\text { Asangani et al (2008), } \\
\text { Sabatel et al (2011) }\end{array}$ & $\begin{array}{l}(60) \\
(61) \\
(62)\end{array}$ \\
\hline$m i R-181 a$ & 1q32.1 & $\begin{array}{l}m i R-181 \text { has a potential role in differentiating } \\
\text { PTC, and BRAF mutation may interact with } \\
m i R-181 \text { in pathogenesis and prognosis of PTC }\end{array}$ & THRB & $\begin{array}{l}\text { Jazdzewski et al (2011), } \\
\text { Sun et al (2013) }\end{array}$ & $\begin{array}{l}(63) \\
(64)\end{array}$ \\
\hline$m i R-197$ & $1 \mathrm{p} 13.3$ & $\begin{array}{l}\text { miR-197 and its target gene may be the novel } \\
\text { molecular markers to differentiate malignant } \\
\text { (FTCs) from benign (FAs) }\end{array}$ & $\begin{array}{l}\text { ACVR1, } \\
\text { TSPAN3 }\end{array}$ & Marini et al (2011) & $(65)$ \\
\hline$m i R-346$ & $10 \mathrm{q} 23.2$ & $\begin{array}{l}m i R-346 \text { participates in the transformation of } \\
\text { follicular tumors from benign to malignant status }\end{array}$ & EFEMP2 & Marini et al (2011) & $(65)$ \\
\hline $\operatorname{miR}-9$ & $1 \mathrm{q} 22$ & $\begin{array}{l}m i R-9 \text { is significantly overexpressed in hereditary } \\
\text { when compared to sporadic medullary thyroid } \\
\text { tumor }\end{array}$ & - & Abraham et al (2011) & $(52)$ \\
\hline$m i R-10 a$ & $17 q 21.32$ & $\begin{array}{l}\text { miR-10a is important for tumor development } \\
\text { in MTC }\end{array}$ & $\begin{array}{l}\text { MDM4 } \\
\text { NCOR2 }\end{array}$ & Hudson et al (2013) & $(66)$ \\
\hline$m i R-124 a$ & $8 p 23.1$ & $m i R-124 a$ is upregulated in MTC & $C D K 6$ & Ajith (2013) & $(67)$ \\
\hline$m i R-127$ & $14 q 23.2$ & $\begin{array}{l}\text { miR-127 is overexpressed in MTC samples } \\
\text { carrying a wild-type RET than mutated RET, } \\
\text { suggesting an oncogenic role for this miRNA }\end{array}$ & BCL6 & Chen et al (2013) & $(68)$ \\
\hline$m i R-224$ & $\mathrm{Xq} 28$ & $\begin{array}{l}m i R-224 \text { upregulation was more detected in } \\
\text { the early stage of MTC }\end{array}$ & - & Mian et al (2012) & $(53)$ \\
\hline $\operatorname{miR}-323$ & $14 q 32.31$ & $m i R-323$ is upregulated in MTC & $B R A F$ & Cahill et al (2007) & $(69)$ \\
\hline
\end{tabular}

higher level in thyroid tumors. Deregulation expression of miR-146b, miR-221 and miR-222 may be the crucial component for initiation and development of PTC (47). The putative target of these miRNAs was suspected to be c-KIT, as a tyrosine kinase receptor that plays an important role in cell growth and differentiation (48). c-KIT is frequently expressed in benign thyroid adenomas and goiter; however its expression decreased to $60 \%$ in FTC and is completely absent in PTC and ATC.

miRNA expression in FTC. The expression level of miR-192, miR-197, miR-328 and miR-346 has been reported to be decreased in FTC compared to follicular adenoma of thyroid gland (FA) (49). These miRNAs are evidently specifically associated with FTC. The expression profile of $m i R-197$ and $m i R-346$ may be associated with transferring follicular tumors from a benign to malignant status. These miRNAs and their target genes may provide the novel molecular markers for differentiation of the malignant status FTC from the benign form (50). By contrast, assessing the role of $m i R-221$ and $m i R-222$ in thyroid carcinomas showed that these molecules are not associated with FTC (51).
miRNA expression in MTC. There are limited numbers of studies that evaluated the role of miRNAs in MTC. According to these aforementioned studies, miRNAs play a pivotal role in the biology of MTC and represent the important class of prognostic biomarker and therapeutic targets. $m i R-9$ has been determined as a specific biomarker in MTC and in sporadic MTC (sMTC). The expression of $m i R-9$ is known to be lower compared to heritable MTC. Overexpression of $m i R-183$ and $m i R-375$ have also been reported as important predictive biomarkers for lateral lymph node metastases (52). The result of one study that examined the association between miRNA expression and RET status in MTC, reported a significant overexpression of miRNA as follows: 4.2-Fold for $m i R-21$, 6.7-fold for $m i R-127,8.8$-fold for $m i R-154,6.6$-fold for $m i R-224,5.8$-fold for $m i R-323,6.1$-fold for $m i R-370,13$-fold for $m i R-9,6.7$-fold for $m i R-183$ and 10.1-fold for $m i R-375$. The upregulation of $m i R-224$ determined it as a prognostic biomarker and the lower level of $m i R-127$ was observed in sMTC that was carrying somatic RET mutation in comparison to sMTC, which was carrying a wild-type RET (53). 


\section{Conclusion}

The epigenetic revolution during the last decades has challenged whether genetic codes are the key determinant for gene function. Studies in epigenetic patterns of cancer have demonstrated that genome packaging is as important as the genome by itself in regulating the essential cellular processes. Understanding the epigenetic alterations is required for molecular treatment design.

As in other types of cancer, the majority of genetic and epigenetic alterations is somatic, and assessing the epigenetic pattern in thyroid cancer revealed a critical role for these alterations in the classification and prognosis of tumors. The reversible epigenetic changes that occur in cancer result in the possibility of epigenetic therapy as an optional treatment. DNA methylation inhibitors were among the first epigenetic drugs proposed for use as cancer therapeutics. Since miRNAs are associated with cell proliferation, differentiation and invasion, these molecules and their biological target genes are considered as potential targets for tumor diagnosis and treatment.

\section{Acknowledgements}

This work is related to Dr Bita Faam by research thesis and supported by Vice Chancellory for Research and Technology Development Ahvaz Jundishapur University of Medical Science. The authors wish to acknowledge Dr Farinaz Afsari for critical comments.

\section{References}

1. Shirazi HA, Hedayati M, Daneshpour MS, Shafiee A and Azizi F: Analysis of loss of heterozygosity effect on thyroid tumor with oxyphilia cell locus in familial non medullary thyroid carcinoma in Iranian families. Indian J Hum Genet 18 340-343, 2012

2. Patel KN and Shaha AR: Poorly differentiated and anaplastic thyroid cancer. Cancer Control 13: 119-128, 2006.

3. Fassnacht M, Kreissl MC, Weismann D and Allolio B: New targets and therapeutic approaches for endocrine malignancies Pharmacol Ther 123: 117-141, 2009.

4. Ghossein R: Problems and controversies in the histopathology of thyroid carcinomas of follicular cell origin. Arch Pathol Lab Med 133: 683-691, 2009.

5. Hedayati M, Zarif Yeganeh M, Sheikhol Eslami S, Rezghi Barez S, Hoghooghi Rad L and Azizi F: Predominant RET germline mutations in exons 10,11 , and 16 in Iranian patients with hereditary medullary thyroid carcinoma. J Thyroid Res 2011: 264248, 2011.

6. Kondo T, Ezzat S and Asa SL: Pathogenetic mechanisms in thyroid follicular-cell neoplasia. Nat Rev Cancer 6: 292-306, 2006.

7. Xing M: BRAF mutation in thyroid cancer. Endocr Relat Cancer 12: 245-262, 2005.

8. Vasko V, Ferrand M, Di Cristofaro J, Carayon P, Henry JF and de Micco C: Specific pattern of RAS oncogene mutations in follicular thyroid tumors. J Clin Endocrinol Metab 88: 2745-2752, 2003.

9. Hedayati M, Nabipour I, Rezaei-Ghaleh N and Azizi F: Germline RET mutations in exons 10 and 11: an Iranian survey of 57 medullary thyroid carcinoma cases. Med J Malaysia 61: 564-569, 2006

10. Nikiforov YE: RET/PTC rearrangement in thyroid tumors. Endocr Pathol 13: 3-16, 2002.

11. Bethanis S, Koutsodontis G, Palouka T, et al: A newly detected mutation of the RET protooncogene in exon 8 as a cause of multiple endocrine neoplasia type 2A. Hormones (Athens) 6: 152-156, 2007.

12. Lips CJ, Höppener JW and Thijssen JH: Medullary thyroid carcinoma: role of genetic testing and calcitonin measurement. Ann Clin Biochem 38: 168-179, 2001.
13. Musholt TJ, Schönefeld S, Schwarz CH, et al: Impact of pathognomonic genetic alterations on the prognosis of papillary thyroid carcinoma. ESES vienna presentation. Langenbecks Arch Surg 395: 877-883, 2010.

14. Kimura ET, Nikiforova MN, Zhu Z, Knauf JA, Nikiforov YE and Fagin JA: High prevalence of BRAF mutations in thyroid cancer: genetic evidence for constitutive activation of the RET/PTC-RAS-BRAF signaling pathway in papillary thyroid carcinoma. Cancer Res 63: 1454-1457, 2003.

15. Nikiforova MN, Kimura ET, Gandhi M, et al: BRAF mutations in thyroid tumors are restricted to papillary carcinomas and anaplastic or poorly differentiated carcinomas arising from papillary carcinomas. J Clin Endocrinol Metab 88: 5399-5404, 2003.

16. Sharma S, Kelly TK and Jones PA: Epigenetics in cancer. Carcinogenesis 31: 27-36, 2010.

17. Egger G, Liang G, Aparicio A and Jones PA: Epigenetics in human disease and prospects for epigenetic therapy. Nature 429: $457-463,2004$

18. Katz TA, Huang Y, Davidson NE and Jankowitz RC: Epigenetic reprogramming in breast cancer: from new targets to new therapies. Ann Med 24: 1-12, 2014.

19. Kondo T, Nakazawa T, Ma D, et al: Epigenetic silencing of TTF-1/NKX2,1 through DNA hypermethylation and histon H3 modification in thyroid carcinoma. Lab invest 89: 791-799, 2009.

20. Moon JW, Lee SK, Lee JO, et al: Identification of novel hypermethylated genes and demethylationg effect of vincristine in colorectal cancer. J Exp Clin Cancer Res 33: 4, 2014.

21. Jones PA and Baylin SB: The epigenomics of cancer. Cell 128: 683-692, 2007

22. Herman JG and Baylin SB: Gene silencing in cancer in association with promoter hypermethylation. N Engl J Med 349: 2042-2054, 2003.

23. Eden A, Gaudet F, Waghmare A and Jaenisch R: Chromosomal instability and tumors promoted by DNA hypomethylation. Science 300: 455, 2003.

24. Lu J, Getz G, Miska EA, et al: MicroRNA expression profiles classify human cancers. Nature 435: 834-838, 2005.

25. Cantley LC and Neel BG: New insights into tumor suppression: PTEN suppresses tumor formation by restraining the phosphoinositide 3-kinase/AKT pathway. Proc Natl Acad Sci USA 96: 4240-4245, 1999.

26. Chu EC and Tarnawski AS: PTEN regulatory functions in tumor suppression and cell biology. Med Sci Monit 10: RA235-RA241, 2004.

27. Alvarez-Nuñez F, Bussaglia E, Mauricio D, et al; Thyroid Neoplasia Study Group: PTEN promoter methylation in sporadic thyroid carcinomas. Thyroid 16: 17-23, 2006.

28. Pfeifer GP and Dammann R: Methylation of the tumor suppressor gene RASSF1A in human tumors. Biochemistry (Mosc) 70: $576-583,2005$.

29. Schagdarsurengin U, Gimm O, Hoang-Vu C, Dralle H, Pfeifer GP and Dammann R: Frequent epigenetic silencing of the $\mathrm{CpG}$ island promoter of RASSF1A in thyroid carcinoma. Cancer Res 62: 3698-3701, 2002.

30. Xing M, Cohen Y, Mambo E, et al: Early occurrence of RASSF1A hypermethylation and its mutual exclusion with BRAF mutation in thyroid tumorigenesis. Cancer Res 64: 1664-1668, 2004.

31. Qi JH, Ebrahem Q, Moore N, et al: A novel function for tissue inhibitor of metalloproteinases-3 (TIMP3): inhibition of angiogenesis by blockage of VEGF binding to VEGF receptor-2. Nat Med 9: 407-415, 2003.

32. Hoque MO, Rosenbaum E, Westra WH, et al: Quantitative assessment of promoter methylation profiles in thyroid neoplasms. J Clin Endocrinol Metab 90: 4011-4018, 2005.

33. Hu S, Liu D, Tufano RP, et al: Association of aberrant methylation of tumor suppressor genes with tumor aggressiveness and BRAF mutation in papillary thyroid cancer. Int J Cancer 119: 2322-2329, 2006

34. De Falco V, Castellone MD, De Vita G, et al: RET/papillary thyroid carcinoma oncogenic signaling through the Rapl small GTPase. Cancer Res 67: 381-390, 2007.

35. Gao L, Feng Y, Bowers R, et al: Ras-associated protein-1 regulates extracellular signal-regulated kinase activation and migration in melanoma cells: two processes important to melanoma tumorigenesis and metastasis. Cancer Res 66: 7880-7888, 2006.

36. Wang Z, Dillon TJ, Pokala V, et al: Rap1-mediated activation of extracellular signal-regulated kinases by cyclic AMP is dependent on the mode of Rap1 activation. Mol Cell Biol 26: 2130-2145, 2006. 
37. Zhang L, Chenwei L, Mahmood R, et al: Identification of a putative tumor suppressor gene RaplGAP in pancreatic cancer. Cancer Res 66: 898-906, 2006.

38. Zhang Z, Mitra RS, Henson BS, et al: Rap1GAP inhibits tumor growth in oropharyngeal squamous cell carcinoma. Am J Pathol 168: 585-596, 2006.

39. Nellore A, Paziana K, Ma C, et al: Loss of Rap1GAP in papillary thyroid cancer. J Clin Endocrinol Metab 94: 1026-1032, 2009.

40. Tsygankova OM, Prendergast GV, Puttaswamy K, et al: Downregulation of Rap1GAP contributes to Ras transformation. Mol Cell Biol 27: 6647-6658, 2007.

41. Rodríguez-Rodero S, Fernández AF, Fernández-Morera JL, et al: DNA methylation signatures identify biologically distinct thyroid cancer subtypes. J Clin Endocrinol Metab 98: 2811-2821, 2013.

42. Ogasawara S, Maesawa C, Yamamoto M, et al: Disruption of cell-type-specific methylation at the Maspin gene promoter is frequently involved in undifferentiated thyroid cancers Oncogene 23: 1117-1124, 2004

43. Xing M, Usadel $\mathrm{H}$, Cohen $\mathrm{Y}$, et al: Methylation of the thyroid-stimulating hormone receptor gene in epithelial thyroid tumors: a marker of malignancy and a cause of gene silencing. Cancer Res 63: 2316-2321, 2003.

44. Faam B, Daneshpour MS, Azizi F, Salehi M and Hedayati M: Association between TPO gene polymorphisms and anti-TPO level in Tehranian population: TLGS. Gene 498: 116-119, 2012.

45. Eze OP, Starker LF and Carling T: The role of epigenetic alterations in papillary thyroid carcinogenesis. J Thyroid Res 2011: 895470, 2011.

46. Xing $M$ : Gene methylation in thyroid tumorigenesis. Endocrinology 148: 948-953, 2007.

47. He H, Jazdzewski K, Li W, et al: The role of microRNA genes in papillary thyroid carcinoma. Proc Natl Acad Sci USA 102: 19075-19080, 2005

48. Kitamura Y and Hirotab S: Kit as a human oncogenic tyrosine kinase. Cell Mol Life Sci 61: 2924-2931, 2004.

49. Weber F, Teresi RE, Broelsch CE, Frilling A and Eng C: A limited set of human MicroRNA is deregulated in follicular thyroid carcinoma. J Clin Endocrinol Metab 91: 3584-3591, 2006.

50. Gallagher WM, Greene LM, Ryan MP, et al: Human fibulin-4: analysis of its biosynthetic processing and mRNA expression in normal and tumour tissues. FEBS Lett 489: 59-66, 2001.

51. Schulte KM, Jonas C, Krebs R and Röher HD: Activin A and activin receptors in thyroid cancer. Thyroid 11: 3-14, 2001.

52. Abraham D, Jackson N, Gundara JS, et al: MicroRNA profiling of sporadic and hereditary medullary thyroid cancer identifies predictors of nodal metastasis, prognosis, and potential therapeutic targets. Clin Cancer Res 17: 4772-4781, 2011.

53. Mian C, Pennelli G, Fassan M, et al: MicroRNA profiles in familial and sporadic medullary thyroid carcinoma: preliminary relationships with RET status and outcome. Thyroid 22: 890-896, 2012.
54. Lagos-Quintana M, Rauhut R, Lendeckel W and Tuschl T: Identification of novel genes coding for small expressed RNAs. Science 294: 853-858, 2001.

55. Frezzetti D, De Menna M, Zoppoli P, et al: Upregulation of miR-21 by Ras in vivo and its role in tumor growth. Oncogene 30 : 275-286, 2011

56. Zuo H, Gandhi M, Edreira MM, et al: Downregulation of Rap1GAP through epigenetic silencing and loss of heterozygosity promotes invasion and progression of thyroid tumors. Cancer Res 70: 1389-1397, 2010.

57. Stephen JK, Chitale D, Narra V, Chen K M, Sawhney R and Worsham MJ: DNA methylation in thyroid tumorigenesis. Cancers (Basel) 3: 1732-1743, 2011.

58. Zhang X, Li D, Li M, et al: MicroRNA-146a targets PRKCE to modulate papillary thyroid tumor development. Int J Cancer 134 257-267, 2014.

59. Visone R, Russo L, Pallante P, et al: MicroRNAs (miR)-221 and miR-222, both overexpressed in human thyroid papillary carcinomas, regulate $\mathrm{p} 27 \mathrm{Kip} 1$ protein levels and cell cycle. Endocr Relat Cancer 14: 791-798, 2007.

60. Meng F, Henson R, Wehbe-Janek H, Ghoshal K, Jacob ST and Patel T: MicroRNA-21 regulates expression of the PTEN tumor suppressor gene in human hepatocellular cancer. Gastroenterology 133: 647-658, 2007.

61. Asangani IA, Rasheed SA, Nikolova DA, et al: MicroRNA-21 (miR-21) post-transcriptionally downregulates tumor suppressor Pdcd 4 and stimulates invasion, intravasation and metastasis in colorectal cancer. Oncogene 27: 2128-2136, 2008.

62. Sabatel C, Malvaux L, Bovy N, et al: MicroRNA-21 exhibits antiangiogenic function by targeting RhoB expression in endothelial cells. PLoS One 6: e16979, 2011.

63. Jazdzewski K, Boguslawska J, Jendrzejewski J, et al: Thyroid hormone receptor beta (THRB) is a major target gene for microRNAs deregulated in papillary thyroid carcinoma (PTC). J Clin Endocrinol Metab 96: E546-E553, 2011.

64. Sun Y, Yu S, Liu Y, Wang F, Liu Y and Xiao H: Expression of miRNAs in papillary thyroid carcinomas is associated with BRAF mutation and clinicopathological features in Chinese patients. Int J Endocrinol 2013: 128735, 2013.

65. Marini F, Luzi E and Brandi ML: MicroRNA role in thyroid cancer development. J Thyroid Res 2011: 407123, 2011.

66. Hudson J, Duncavage E, Tamburrino A, et al: Overexpression of miR-10a and miR-375 and downregulation of YAP1 in medullary thyroid carcinoma. Exp Mol Pathol 95: 62-67, 2013.

67. Ajith TA: Physiological relevance and theraeutic value of micro RNA in cancer. Front Pathol Genet 1: 15-19, 2013

68. Chen J, Wang M, Guo M, Xie Y and Cong YS: miR-127 regulates cell proliferation and senescence by targeting BCL6. PLoS One 8: e80266, 2013.

69. Cahill S, Smyth P, Denning K, et al: Effect of BRAFV600E mutation on transcription and post-transcriptional regulation in a papillary thyroid carcinoma model. Mol Cancer 6: 21, 2007. 